\title{
Force fields for nitriles
}

\author{
ReIzo YamaderA* and S. KRIMM \\ Harrison M. Randall Laboratory of Physics, The University of Michigan \\ Ann Arbor, Michigan \\ (Received 15 January 1968)
}

\begin{abstract}
A valence force field for nitriles based on the force field obtained for hydrocarbons is found to give very good agreement with the observed bands for several mono- and di-nitrile molecules. The average deviation between observed and calculated frequencies for the 238 assigned frequencies is $0.98 \%$. This is a significant improvement over the results obtained previously with a Urey-Bradley force field.
\end{abstract}

\section{INTRODUCTION}

A NUMBER of studies have been devoted to the analysis of the spectra of small molecules containing the $\mathrm{C} \equiv \mathrm{N}$ group. These have included experimental studies and band assignments on molecules with one $\mathrm{C} \equiv \mathrm{N}$ group, such as acetonitriles [1-7] and propionitrile [8], as well as on molecules with two $\mathrm{C} \equiv \mathrm{N}$ groups, such as malononitrile $[9,10]$, succinonitrile [11-13], and glutaronitrile [14]. Some of these studies $[5,6,8-11,13]$ have included, and others $[15,16]$ have been devoted to, normal coordinate calculations of the vibrational frequencies. In the more recent work a Urey-Bradley force field was the basis for this analysis.

Recent studies of hydrocarbons have led to the development of a valence force field $[17,18]$ which appears to provide a more complete representation of the internal

\footnotetext{
* Permanent address: Textile Research Institute, Toyobo Company Ltd., Katata, Shiga, Japan.

[1] P. Venkateswari, $J$. Chem. Phys. 19, 293 (1951); 20, 923 (1952).

[2] H. W. Thompson and R. L. Williams, Trans. Faraday Soc. 48, 502 (1952).

[3] F. W. Parker, A. H. Nielsen and W. H. Fletcher, J. Mol. Spectry 1, 107 (1957).

[4] R. D. Dick and A. G. Meister, J. Mol. Spectry 5, 170 (1960).

[5] M. G. K. Pillai and F. F. Clevverand, J. Mol. Spectry 5, 212 (1960).

[6] I. Nakagawa and T. Shimavouchi, Spectrochim. Acta 18, 513 (1962).

[7] W. H. Fletcher and C. S. ShovP, J. Mol. Spectry 10, 300 (1963).

[8] N. E. Dundan and G. J. JANZ, J. Chem. Phys. 23, 434 (1955).

[9] F. Halverson and R. J. Francel, J. Chem. Phys. 17, 694 (1949).

[10] T. Fujiyama and T. Shrmanouche, Spectrochim. Acta 20, 829 (1964).

[11] W. E. FitzGERALD and G. J. JANZ, J. Mol. Spectry 1, 49 (1957).

[12] I. Matsubara, Bull. Chem. Soc. Japan 34, 1710 (1961).

[13] T. Fujiyama, K. Tokumaru and T. Shimanouchi, Spectrochim. Acta 20, 415 (1964).

[14] I. Matsubana, Bull. Chem. Soc. Japan 34, 1719 (1961).

[15] S. L. N. G. KRIShNaMachari, Indian J. Phys. 28, 463 (1954).

[16] W. H. Fletcher and C. S. Shoup, Int. Symp. Mol. Struct. Spectry, Tokyo. Preprint C204 (1962).

[17] J. H. Schachtschneider and R. G. Snyder, J. Polymer Sci. C7, 99 (1964).

[18] R. G. SNYDER and J. H. SchachtSCHNEIDER, Spectrochim. Acta 21, 169 (1965).
} 
potential energy than does the Urey-Bradley force field. This valence force field has been transferred satisfactorily to other small molecules, such as those containing chlorine atoms [19]. We report here its extension to molecules with $\mathrm{C} \equiv \mathrm{N}$ groups, and compare the results with those obtained from the Urey-Bradley force field.

Table 1. Nitrile molecules for which normal coordinate calculations were done

\begin{tabular}{|c|c|c|c|c|c|}
\hline Molecule & Formula & $\begin{array}{l}\text { Molecular } \\
\text { symmetry }\end{array}$ & Number of fundamentals & & $\begin{array}{c}\text { Average devia } \\
\text { tion between } \\
\text { observed and } \\
\text { calculated } \\
\text { frequencies } \\
(\%)\end{array}$ \\
\hline Acetonitrile & $\mathrm{CH}_{8} \mathrm{CN}$ & $C_{3 v}$ & $4(A)+4(E)+4\left(E^{\prime}\right)$ & $=12$ & 0.28 \\
\hline Acetonitrile- $d_{3}$ & $\mathrm{CD}_{3} \mathrm{CN}$ & $C_{30}$ & $4(A)+4(E)+4\left(E^{\prime}\right)$ & $=12$ & 0.73 \\
\hline Propionitrile & $\mathrm{CH}_{8} \mathrm{CH}_{8} \mathrm{CN}$ & $C_{*}^{20}$ & $13\left(A^{\prime}\right)+8\left(A^{\prime}\right)$ & $=21$ & 0.71 \\
\hline Isobutyronitrile & $\mathrm{CH}_{3} \mathrm{CH}(\mathrm{CN}) \mathrm{CH}_{8}$ & $C_{s}$ & $17\left(A^{\prime}\right)+13\left(A^{\prime \prime}\right)$ & $=\mathbf{3 0}$ & 0.56 \\
\hline Malononitrile & $\mathrm{NCCH}_{2} \mathrm{CN}$ & $C_{\mathrm{gp}}$ & $6\left(A_{1}\right)+2\left(A_{2}\right)+4\left(B_{1}\right)+3\left(B_{2}\right)$ & $==15$ & 0.96 \\
\hline Malononitrile- $d_{1}$ & NCCHDCN & $C$ & $9\left(A^{\prime}\right)+6\left(A^{\prime \prime}\right)$ & $=15$ & 1.25 \\
\hline Malononitrile- $d_{2}$ & $\mathrm{NCCD}_{2} \mathrm{CN}$ & $C_{2 v}$ & $6\left(A_{1}\right)+2\left(A_{2}\right)+4\left(B_{1}\right)+3\left(B_{2}\right)$ & $=15$ & 1.09 \\
\hline $\begin{array}{l}\text { Succinonitrile } \\
\text { (trans) }\end{array}$ & $\mathrm{NCCH}_{2} \mathrm{CH}_{8} \mathrm{CN}(T)$ & $C_{2 \mathrm{a}}$ & $8\left(A_{v}\right)+5\left(A_{u}\right)+4\left(B_{v}\right)+7\left(B_{u}\right)$ & $=24$ & 1.30 \\
\hline $\begin{array}{l}\text { Suocinonitrile } \\
\text { (gauche) }\end{array}$ & $\mathrm{NCCH}_{2} \mathrm{CH}_{8} \mathrm{CN}(\theta)$ & $C_{2}$ & $13(A)+11(B)$ & $=24$ & 1.08 \\
\hline $\begin{array}{l}\text { Glutaronitrile } \\
\text { (trans-trans) }\end{array}$ & $\mathrm{NCCH}_{2} \mathrm{CH}_{2} \mathrm{CH}_{2} \mathrm{CN}(T T)$ & $C_{2 v}$ & \multicolumn{2}{|c|}{$11\left(A_{1}\right)+6\left(A_{2}\right)+9\left(B_{1}\right)+7\left(B_{2}\right)=33$} & 1.13 \\
\hline $\begin{array}{l}\text { Glutaronitrile } \\
\text { (trans-gauche) }\end{array}$ & $\mathrm{NCCH}_{2} \mathrm{CH}_{2} \mathrm{CH}_{2} \mathrm{CN}(T G)$ & $C_{\mathbf{2}}$ & $17(A)+16(B)$ & $=\mathbf{3 3}$ & 1.01 \\
\hline $\begin{array}{l}\text { Glutaronitrile } \\
\text { (gauche-gauche) }\end{array}$ & $\mathrm{NCCH}_{2} \mathrm{CH}_{2} \mathrm{CH}_{2} \mathrm{CN}(G G)$ & $C_{1}$ & $33(A)$ & $=33$ & 1.21 \\
\hline
\end{tabular}

Our force field has provided a useful basis for the analysis of the vibrational spectrum of polyacrylonitrile [20].

\section{Calculations and Results}

Normal coordinate calculations were done on the 12 molecules listed in Table 1. The Wilson $G F$ matrix method [21] was used, and the torsional coordinate for rotation about the $\mathrm{C}-\mathrm{C}$ bond was included according to the method of Mryazawa and Fuk UShima [22]. The computations were performed on an IBM 7090 computer. The molecular constants used in the calculation were as follows: $r(\mathrm{C}-\mathrm{C})=1.54 \AA$, $r(\mathrm{C}-\mathrm{N})=1.17 \AA, r(\mathrm{C}-\mathrm{CN})=1.47 \AA, r(\mathrm{C}-\mathrm{H})=1.10 \AA, \Varangle \mathrm{C}-\mathrm{C}-\mathrm{N}=180^{\circ}$, all other angles tetrahedral (standard values of the masses were used).

The procedure which was used was to start with the valence force field constants which had been obtained for the hydrocarbons [17, 18]. To these were added appropriate force constants associated with the $\mathrm{C} \equiv \mathrm{N}$ group(s). The values of the latter were determined by seeking a best fit to the observed frequencies, in one case (acetonitrile) by means of a least squares refinement procedure and in the other cases by means of adjustments based on examination of the Jacobian. In some instances

[19] C. G. OPASKar and S. KRTMM, Spectrochim. Acta 23A, 2261 (1967).

[20] R. Yamadera and S. KRIMM, Int. Symp. Macromol. Chem. Tokyo-Kyoto, 1965. Preprint 2.5.02, to be published.

[21] E. B. WILson, JR., J. C. Jecrus and P. C. Cross Molecular Vibrations. McGraw.Hill (1955).

[22] T. Mryazawa and K. Fukushrma, J. Mol. Spectry 15, 308 (1965). 
Table 2. Valence force field constants for nitrile molecules

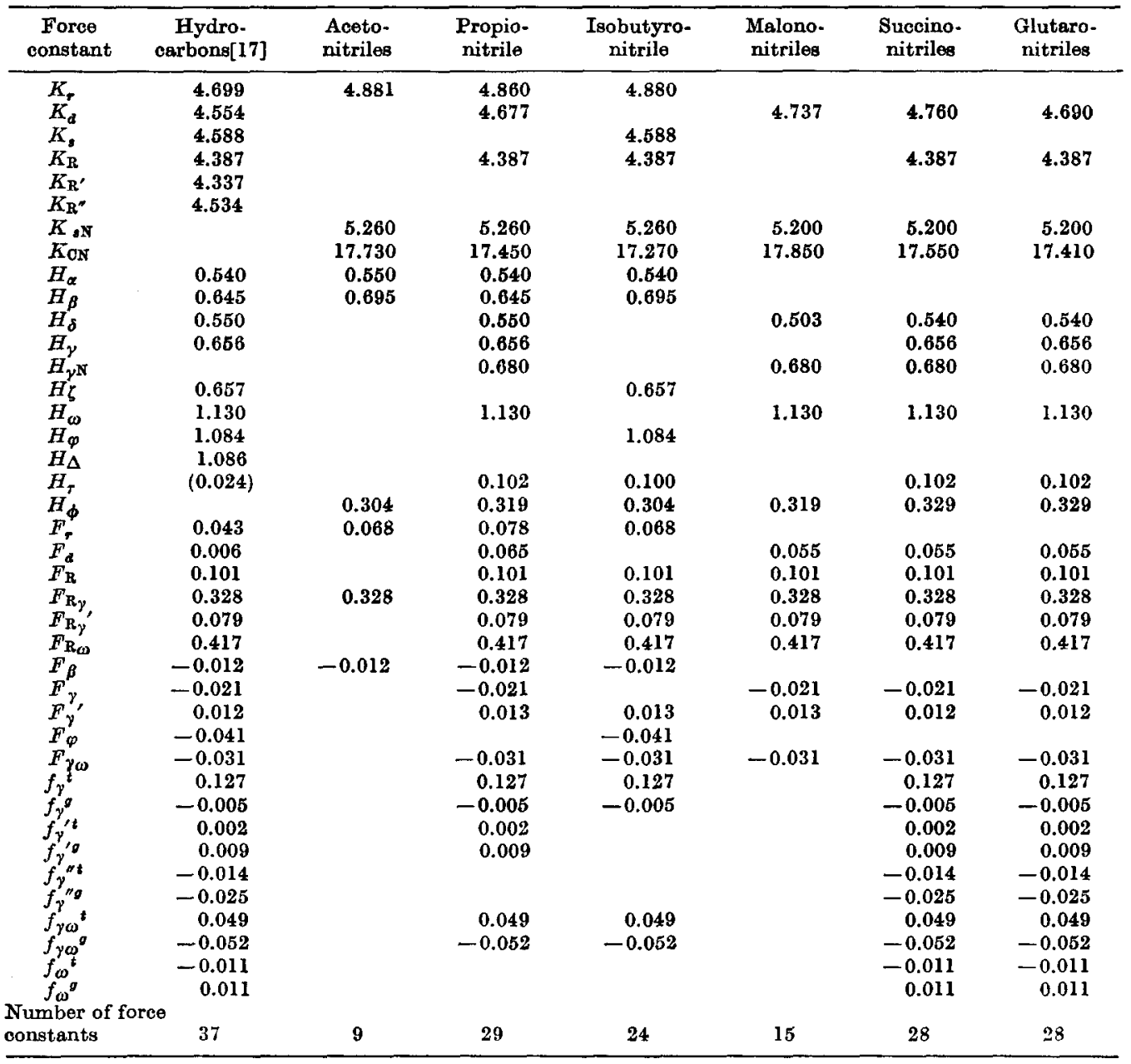

slight modifications in the diagonal valence force field constants were necessary in order to obtain optimum agreement between observed and calculated frequencies. The final sets of force constants are given in Table 2. The notation follows that previously used $[17,18]$, except for $K_{a \mathrm{~N}}, K_{\mathrm{CN}}, H_{\phi}$, and $H_{\gamma_{\mathrm{N}}}$ which represent force constants for $\mathrm{C}-\mathrm{CN}$ stretching, $\mathrm{C} \equiv \mathrm{N}$ stretching, $\mathrm{C}-\mathrm{C} \equiv \mathrm{N}$ bending, and $\mathrm{C}-\mathrm{C}-\mathrm{H}$ bending in the $-\mathrm{CH}_{2}-\mathrm{CN}$ group, respectively.

The calculated frequencies are compared with observed frequencies in Tables 3-8. The potential energy distributions in the normal modes are also given, only contributions greater than $15 \%$ being listed.

\section{Acetonitrile}

\section{Discussion}

Normal coordinate calculations on acetonitrile have been made using a valence force field [5], a Urey-Bradley force field [6], and an orbital valency force field [16]. 
Table 3. Observed and calculated frequencies of acetonitriles

\begin{tabular}{|c|c|c|c|c|c|c|c|}
\hline & $\bar{v}_{\text {obs }}[6]$ & $\bar{\nu}_{\text {calc }}[6]$ & $\bar{v}_{\text {obs }}[16]$ & $\bar{v}_{\text {calc }}[16]$ & $\bar{v}_{\text {calc }}[5]$ & \multicolumn{2}{|c|}{$\tilde{y}_{\text {cale }}(\mathrm{VFF})$} \\
\hline \multicolumn{8}{|c|}{$\mathrm{CH}_{3} \mathrm{CN}$} \\
\hline $\begin{array}{l}v_{1} \\
v_{2} \\
\nu_{3} \\
v_{4} \\
v_{5} \\
v_{6} \\
\nu_{7} \\
\nu_{8} \\
\zeta_{5} \\
\zeta_{8} \\
\zeta_{7} \\
\zeta_{8}\end{array}$ & $\begin{array}{c}2954 \\
2267 \\
1385 \\
920 \\
3009 \\
1453 \\
1041 \\
362 \\
0.062 \\
-0.384 \\
0.422 \\
0.945\end{array}$ & $\begin{array}{c}3003 \\
2276 \\
1361 \\
916 \\
2961 \\
1470 \\
1041 \\
359 \\
0.065 \\
-0.363 \\
0.423 \\
0.913\end{array}$ & $\begin{array}{c}2954.2 \\
2266.7 \\
1389 \\
920.3 \\
3009.1 \\
1454.2 \\
1040.8 \\
361.0 \\
0.073 \\
-0.39 \\
0.422 \\
0.93\end{array}$ & $\begin{array}{r}2947.6 \\
2267.3 \\
1388.5 \\
921.7 \\
3035.0 \\
1451.6 \\
1041.6 \\
361.6 \\
0.14 \\
-0.41 \\
0.45 \\
0.91\end{array}$ & $\begin{array}{r}2980 \\
2231 \\
1396 \\
920 \\
3009 \\
1454 \\
1041 \\
361\end{array}$ & $\begin{array}{r}2953 \\
2268 \\
1387 \\
920 \\
3009 \\
1452 \\
1048 \\
357 \\
0.15 \\
-0.37 \\
0.33 \\
0.92\end{array}$ & $\begin{array}{l}\nu_{\mathrm{s}}\left(\mathrm{CH}_{8}\right)(99) \\
\nu(\mathrm{CN})(89) \\
\delta_{\mathrm{S}}\left(\mathrm{CH}_{3}\right)(93) \\
\nu(\mathrm{CCN})(88) \\
\nu_{\mathrm{a}}\left(\mathrm{CH}_{3}\right)(99) \\
\delta_{\mathrm{a}}\left(\mathrm{CH}_{3}\right)(91) \\
\tau\left(\mathrm{CH}_{3}\right)(89) \\
\delta(\mathrm{CN})\left(98_{1}\right)\end{array}$ \\
\hline \multicolumn{8}{|c|}{$\mathrm{CD}_{3} \mathrm{CN}$} \\
\hline $\begin{array}{l}v_{1} \\
\nu_{2} \\
v_{3} \\
v_{4} \\
v_{5} \\
v_{6} \\
v_{7} \\
\nu_{8} \\
\zeta_{5} \\
\zeta_{8} \\
\zeta_{7} \\
\zeta_{8}\end{array}$ & & & $\begin{array}{r}2125.6 \\
2277.6 \\
1110 \\
831.3 \\
2256.6 \\
1046.4 \\
846.4 \\
331.2 \\
0.14 \\
-0.40 \\
0.45 \\
0.86\end{array}$ & $\begin{array}{r}2114.2 \\
2277.5 \\
1110.5 \\
829.3 \\
2247.1 \\
1049.1 \\
846.2 \\
330.2 \\
0.25 \\
-0.46 \\
0.47 \\
0.83\end{array}$ & & $\begin{array}{r}2121 \\
2273 \\
1103 \\
833 \\
2244 \\
1042 \\
826 \\
335 \\
0.27 \\
-0.43 \\
0.37 \\
0.85\end{array}$ & $\begin{array}{l}\nu_{\mathrm{s}}\left(\mathrm{CD}_{3}\right)(95) \\
\nu(\mathrm{CN})(84) \\
\delta_{\mathrm{s}}\left(\mathrm{CD}_{\mathrm{g}}\right)(67), \nu(\mathrm{CCN})(30) \\
\nu\left(\mathrm{CCN}^{2}\right)(66), \delta_{\mathrm{g}}\left(\mathrm{CD}_{\mathrm{s}}\right)(24) \\
\nu_{\mathrm{a}}\left(\mathrm{CD}_{3}\right)(98) \\
\delta_{\mathrm{a}}\left(\mathrm{CD}_{\mathrm{s}}\right)(95) \\
r\left(\mathrm{CD}_{3}\right)(89) \\
\delta(\mathrm{CCN})(94)\end{array}$ \\
\hline
\end{tabular}

$y_{\mathrm{B}, \mathrm{a}}$ : (symmetric, antisymmetric) stretching; $\delta_{\mathrm{B}, \mathrm{a}}$ : (symmetric, antisymmetric) bending; $r$ : rocking.

Table 4. Observed and calculated frequencies of propionitrile

\begin{tabular}{|c|c|c|c|}
\hline Infrared & Raman & \multicolumn{2}{|c|}{$\bar{\nu}_{\text {ealc }}(\mathrm{VFF})$} \\
\hline $\begin{array}{l}2999 \mathrm{vs} \\
2958 \mathrm{~s} \\
2958 \mathrm{~s} \\
2900 \mathrm{~s} \\
2252 \mathrm{~s} \\
1461 \mathrm{vs} \\
1431 \mathrm{~s} \\
1380 \mathrm{~m} \\
1316 \mathrm{~m} \\
1260 \mathrm{vw} \\
1090 \mathrm{vvw} \\
1075 \mathrm{~s} \\
1004 \mathrm{~m} \\
836 \mathrm{w} \\
784 \mathrm{~s} \\
545 \mathrm{~m} \\
\\
(236 ?)\end{array}$ & $\begin{array}{l}3001 \mathrm{~s} \mathrm{dp} \\
2949 \mathrm{vs} \\
2898 \mathrm{~s} \\
2251 \mathrm{vs} p \\
1466 \mathrm{~m} \mathrm{dp} \\
1436 \mathrm{mp} \\
1374 \mathrm{vw} p \\
1322 \mathrm{w} \mathrm{p} \\
1270 \mathrm{vw} \mathrm{dp} \\
1078 \mathrm{mp} \\
1010 \mathrm{~s} \mathrm{p} \\
838 \mathrm{~s} \mathrm{p} \\
784 \mathrm{vw} \mathrm{dp} \\
548 \mathrm{~m} \mathrm{p} \\
378 \mathrm{~m} \mathrm{dp} \\
226 \mathrm{~m} \mathrm{dp}\end{array}$ & $\begin{array}{l}3001 A^{\prime} \\
3001 A^{\prime \prime} \\
2952 A^{\prime} \\
2947 A^{\prime \prime} \\
2912 A^{\prime} \\
2252 A^{\prime} \\
1457 A^{\prime} \\
1451 A^{\prime \prime} \\
1445 A^{\prime} \\
1364 A^{\prime} \\
1308 A^{\prime} \\
1261 A^{\prime \prime} \\
1092 A^{\prime \prime} \\
1061 A^{\prime} \\
1025 A^{\prime} \\
831 A^{\prime} \\
776 A^{\prime \prime} \\
528 A^{\prime} \\
375 A^{\prime \prime} \\
236 A^{\prime} \\
226 A^{\prime \prime}\end{array}$ & $\begin{array}{l}\nu_{\mathrm{a}}\left(\mathrm{CH}_{3}\right)(99) \\
\nu_{\mathrm{a}}\left(\mathrm{CH}_{3}\right)(99) \\
\nu_{\mathrm{s}}\left(\mathrm{CH}_{3}\right)(99) \\
\nu_{\mathrm{a}}\left(\mathrm{CH}_{2}\right)(99) \\
\nu_{\mathrm{s}}\left(\mathrm{CH}_{2}\right)(99) \\
\nu(\mathrm{CN})(88) \\
\delta_{\mathrm{a}}\left(\mathrm{CH}_{3}\right)(58), \delta\left(\mathrm{CH}_{2}\right)(33) \\
\delta_{\mathrm{a}}\left(\mathrm{CH}_{3}\right)(92) \\
\delta\left(\mathrm{CH}_{2}\right)(66), \delta_{\mathrm{a}}\left(\mathrm{CH}_{3}\right)(30) \\
\delta_{\mathrm{s}}\left(\mathrm{CH}_{3}\right)(83) \\
w\left(\mathrm{CH}_{2}\right)(65) \\
t\left(\mathrm{CH}_{2}\right)(83) \\
r_{\mathrm{a}}\left(\mathrm{CH}_{3}\right)(38), r(\mathrm{CH})(34) \\
r_{\mathrm{s}}(\mathrm{CH})(48), \nu(\mathrm{CO})(16) \\
\nu(\mathrm{CC})(66), \nu(\mathrm{CCN})(19) \\
\nu(\mathrm{CCN})(50), r_{\mathrm{s}}(\mathrm{CH},)(23) \\
r(\mathrm{CH})(51), r_{\mathrm{a}}(\mathrm{CH})(39) \\
\delta(\mathrm{CCC})(52), \delta_{i}(\mathrm{CCN})(34) \\
\delta_{o}(\mathrm{CCN})(83) \\
\delta_{i}(\mathrm{CCN})(63), \delta(\mathrm{CCC})(34) \\
\tau(81)\end{array}$ \\
\hline
\end{tabular}

vs: very strong; s: strong; m: medium; w: weak; p: polarized; dp; depolarized. Symbols for internal coordinates same as in Table 3, plus: $w$ : wagging; $t$ : twisting; $\delta_{i, 0}$ : (in-plane, out-of-plane) bending; $\tau$ : torsion. 
Table 5. Observed and calculated frequencies of isobutyronitrile

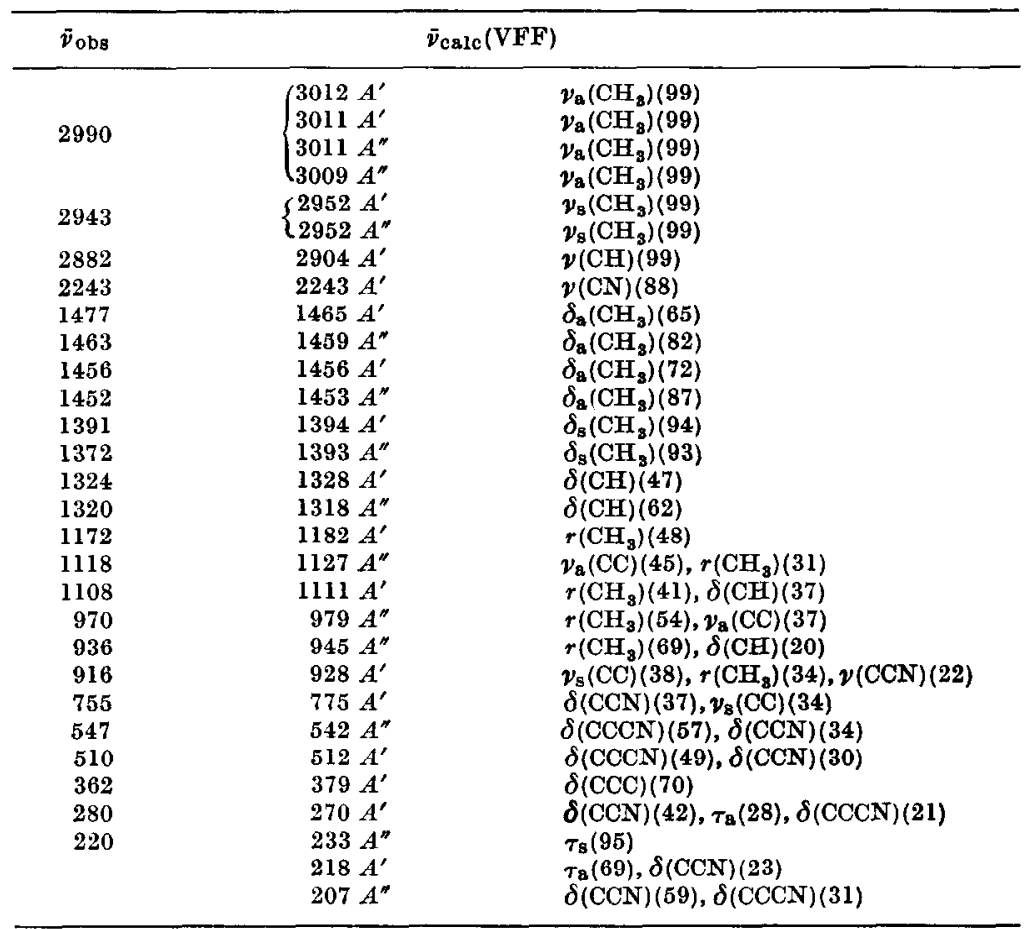

The results of these calculations are given in Table 3, together with the frequencies calculated from our valence force field for acetonitrile and acetonitrile- $d_{3}$. The average deviation between observed and calculated frequencies, viz., $0.28 \%$, (cf. Table 1), compares favorably with that obtained from the orbital valency force field [16], viz., $0.22 \%$, is better than that from the earlier valence force field [5], which gives $0.38 \%$, and is much better than what is obtained from the Urey-Bradley force field, viz., $0.98 \%$. Using our force constants we have also computed Coriolis coupling constants for acetonitrile and acetonitrile- $d_{3}$, using the $C$-matrix method of MEAL and PoLo [23]. These are listed in Table 3, and are in reasonable agreement with the observed values.

\section{Propionitrile}

The vibrational spectrum of propionitrile has been studied both in the infrared and Raman [8]. The observed frequencies, as well as the polarizations of the Raman bands are listed in Table 4 together with our calculated frequencies. The assignments suggested in Table 4 are in good agreement with the symmetry species of the bands determined from the polarizations of the Raman lines. In those cases (2999 and 3001, 1461 and 1466) where assignments of apparently single bands are made to two predicted modes, such assignments are indicated by the contour of the vapor phase bands [8]. The band at 1090 is wcakly indicated in the spectrum; and the band at $236 \mathrm{~cm}^{-1}$ is hypothesized from the presence in the infrared spectrum of a

[23] J. H. Meal and S. R. Poro, J. Chem. Phys. 24, 1126 (1956). 
Table 6. Observed and calculated frequencies of malononitriles

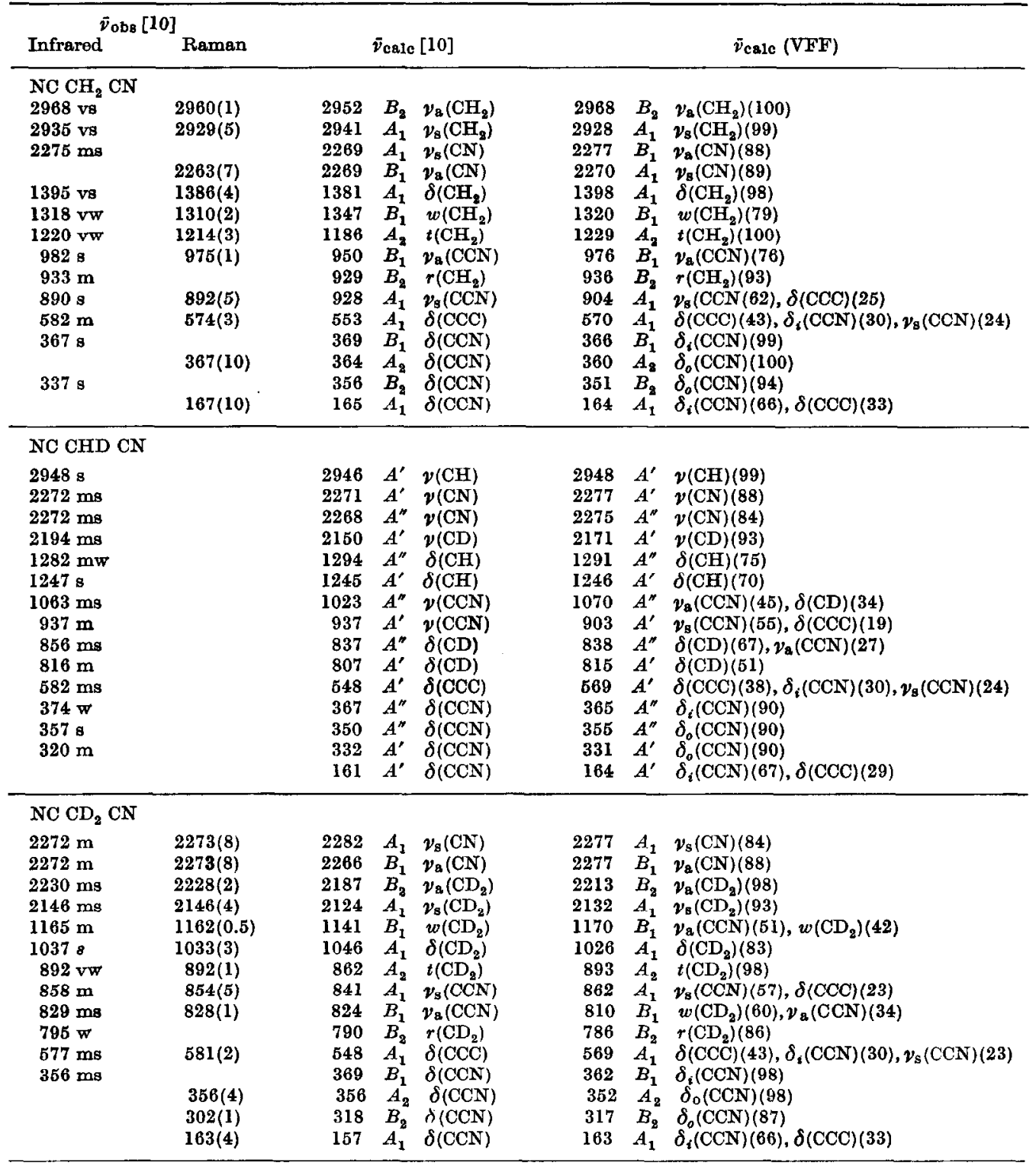

weak band at $471 \mathrm{~cm}^{-1}$, which is taken to be an overtone. It will be seen that our force field is in quite satisfactory agreement with the observed spectrum.

\section{I sobutyronitrile}

A further check of our valence force field for molecules with one $\mathrm{C} \equiv \mathrm{N}$ group is provided by a calculation of the frequencies of isobutyronitrile. These are shown in Table 5. The spectrum of this molecule has not been reported on, and in Fig. I we show an infrared spectrum of this material in the liquid state (obtained on a Beckmann 


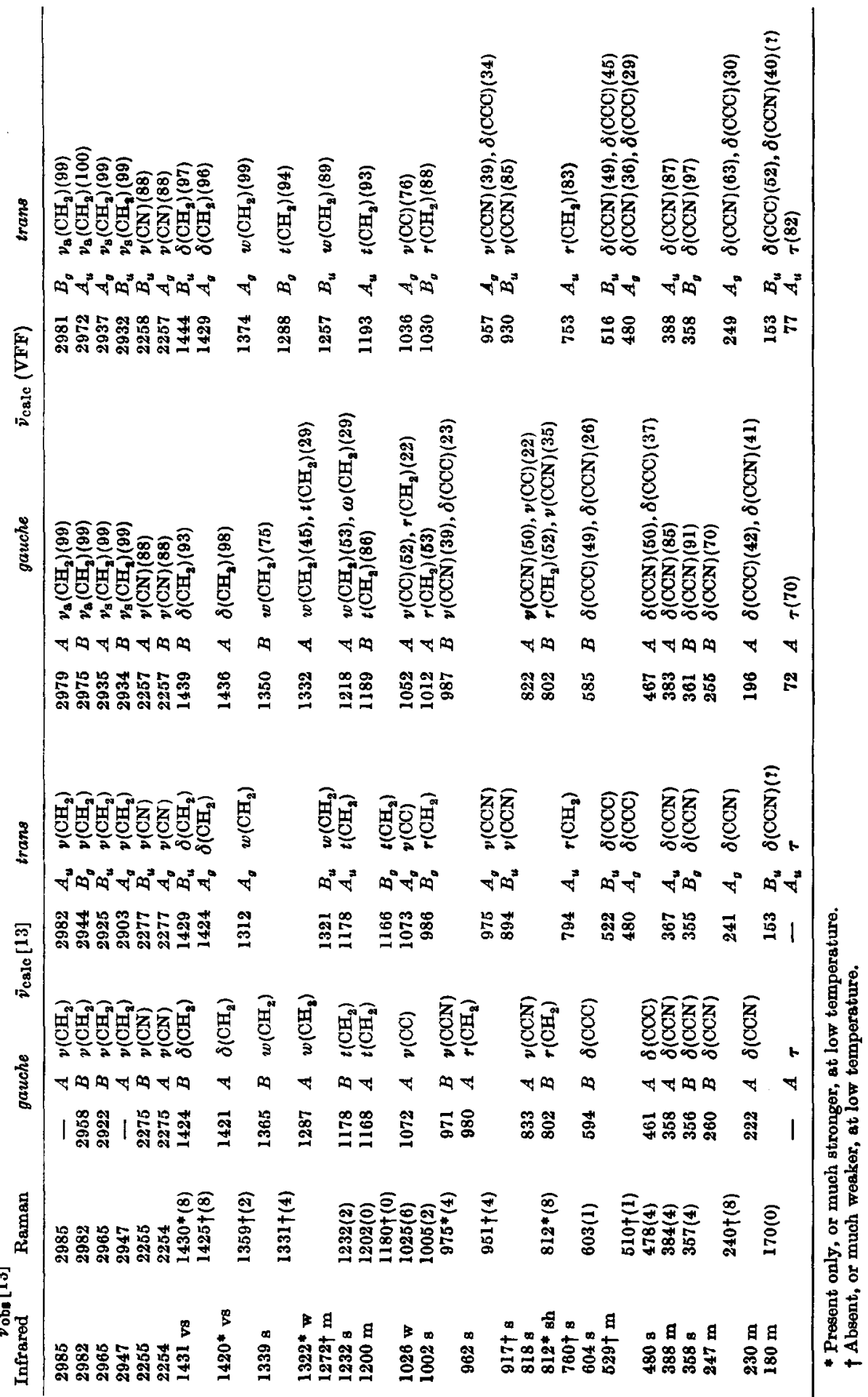


Table 8. Observed and calculated frequencies of glutaronitriles

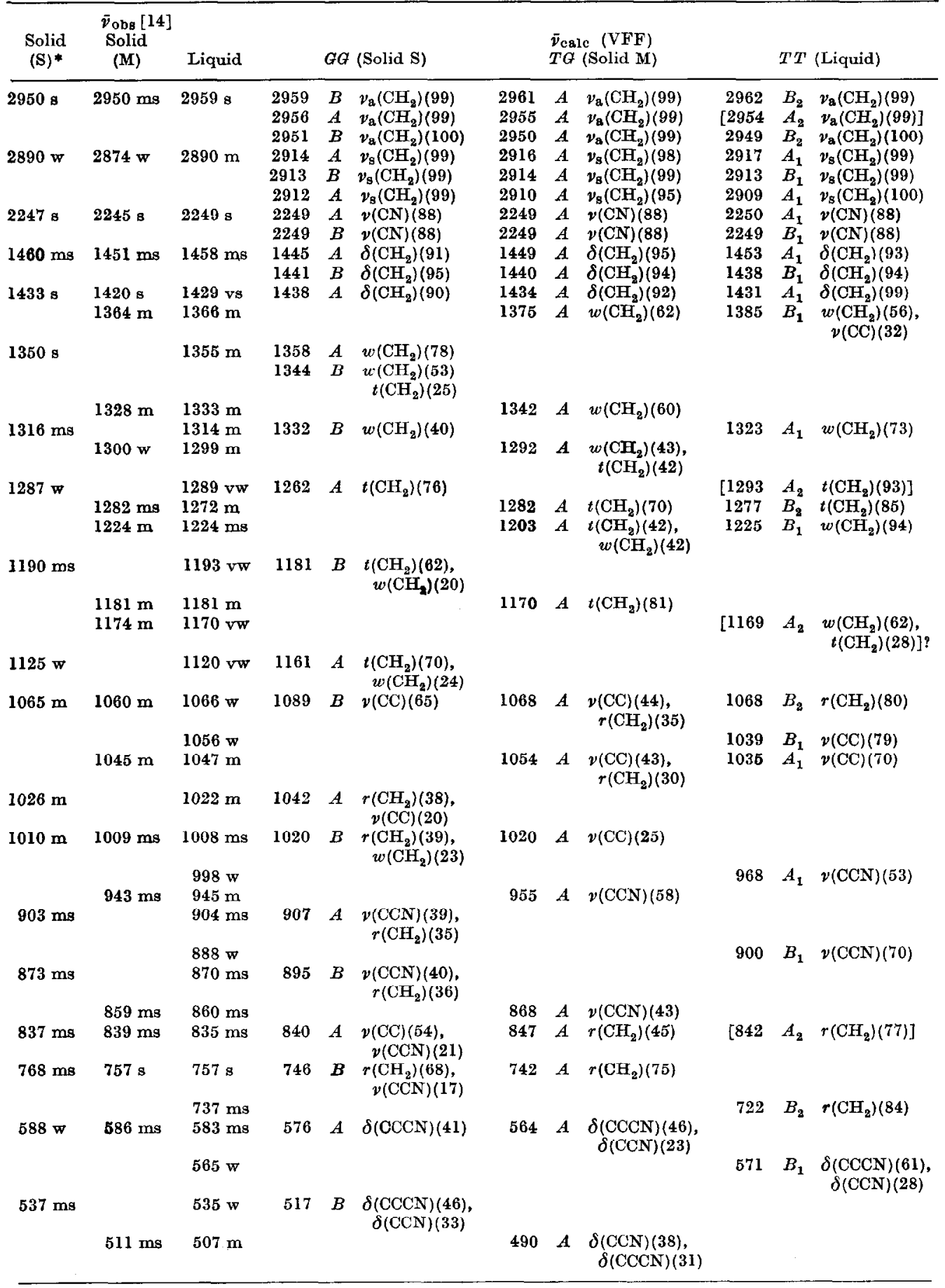


Table 8 (cont.)

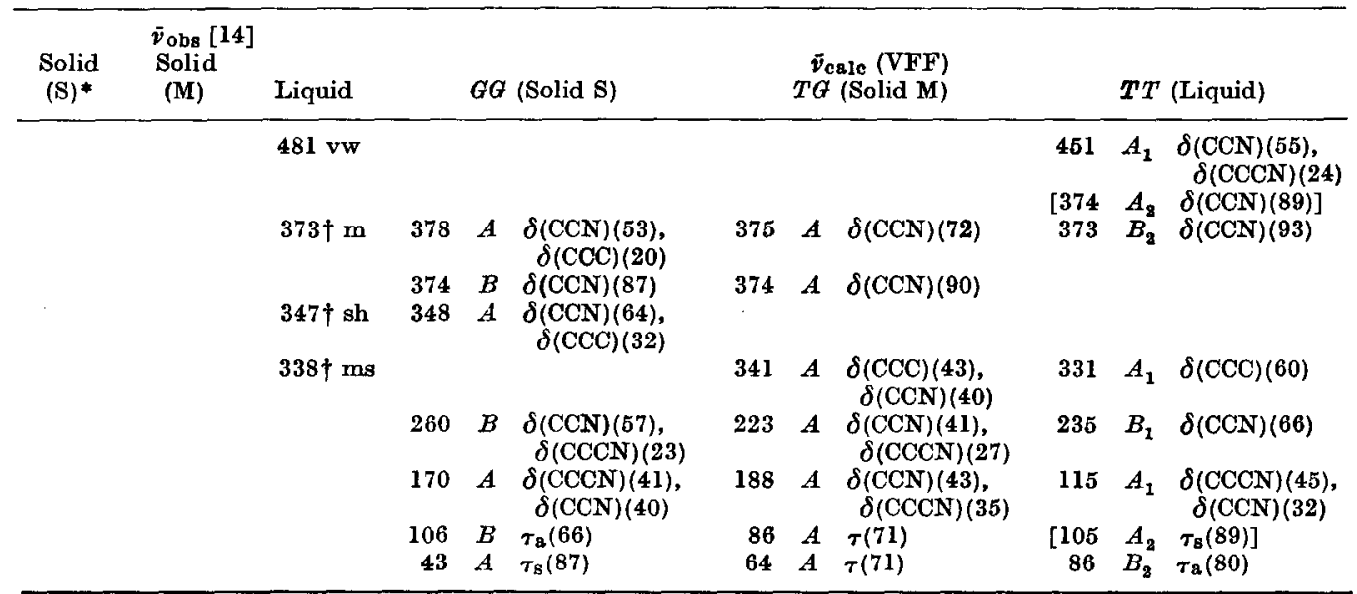

- Solid $(S)=$ stable solid, Solid $(M)=$ metastable solid.

$\dagger$ New bands observed in present work.

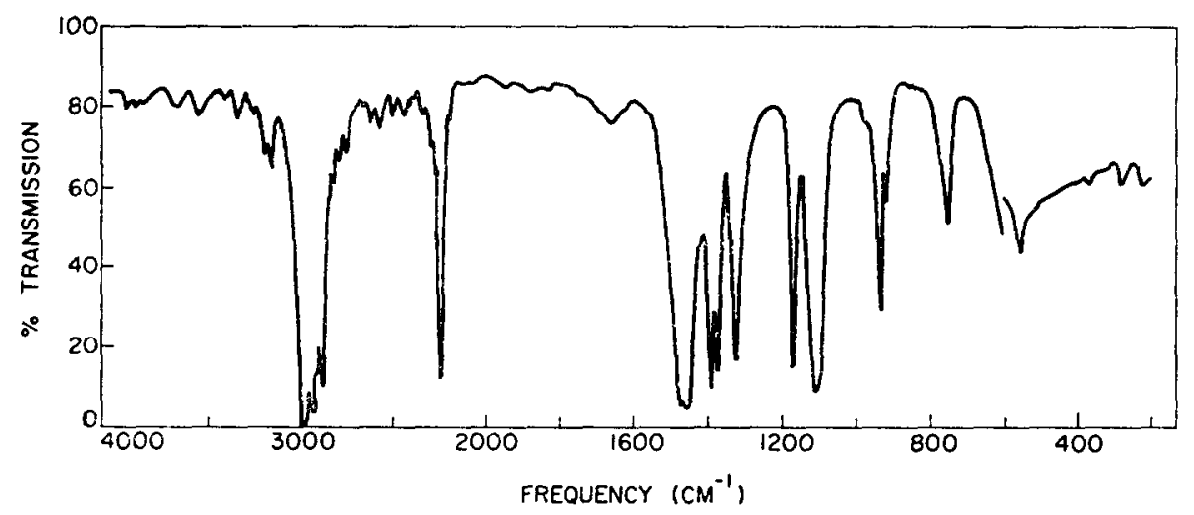

Fig. 1. Infrared spectrum of isobutyronitrile.

IR-12 spectrometer). The observed bands are listed in Table 5, and an assignment based on frequency correlation is suggested. This of course is not decisive, and other evidence for band assignments is desirable (for example, polarization of Raman lines). It will be seen, however, that reasonable agreement is achieved between observed and calculated frequencies with force constants which are essentially transferred from the hydrocarbons and acetonitrile.

\section{Malononitrile}

Malononitrile is the simplest example of a nitrile with two $\mathrm{C} \equiv \mathrm{N}$ groups. Because of the attachment of the two $\mathrm{C} \equiv \mathrm{N}$ groups to the same carbon atom, some of the force constants have had to be modificd slightly as compared to their valucs in molecules with one $\mathrm{C} \equiv \mathrm{N}$ group (cf. Table 2). Calculations have been done on malononitrile, malononitrile- $d_{1}$, and malononitrile- $d_{2}$, for which infrared and Raman data are available [10]. The observed and calculated frequencies are given in Table 6, where they are compared with calculations based on a Urey-Bradley force field [10]. 
The latter calculations give average deviations between observed and calculated frequencies of $1.89 \%, 1.61 \%$, and $2.07 \%$ for the above three molecules respectively, compared to our values of $0.96 \%, 1.25 \%$, and $1.09 \%$. This again suggests that the valence force field may provide a better representation of the internal potential energy of a molecule than the Urey-Bradley force field.

\section{Succinonitrile}

The vibrational spectrum of succinontrile has been the subject of three recent papers [11-13]. This molecule can exist in two rotationally isomeric forms, a trans and a gauche conformation. Both are present at room temperature, but only the gauche form is stable below $-50^{\circ} \mathrm{C}[11]$. The latter form can also be stabilized in a copper nitrate coordination compound [12], and this as well as the temperature study have permitted an assignment of bands to be made to the trans and gauche structures. A recent calculation of the predicted spectrum has been made using a UreyBradley force field [13]. In Table 7 we compare the observed infrared and Raman bands with these calculations and with the results obtained using our valence force field. The results are substantially the same as obtained previously [13], although our calculations suggest some modifications in assignments. The overall agreement using the valence force field is again somewhat better (giving average deviations of $1.30 \%$ and $1.08 \%$ for the trans and gauche structures respectively) than is obtained with the Urey-Bradley field (which gives average deviations of $2.41 \%$ and $2.22 \%$ for these two structures).

\section{Glutaronitrile}

Glutaronitrile can exist in three rotationally isomeric forms, trans-trans $(T T)$, trans-gauche $\left(T^{\prime} G\right)$, and gauche-gauche $(G G)$. ('The fourth form, $G G^{\prime}$, is sterically and electrically unfavorable.) Experimental studies of this molecule [14] indicate that the $G G$ form is the stable structure in the crystalline solid. A metastable crystalline form is obtained by rapid cooling to $-60^{\circ} \mathrm{C}$, and it has been suggested that the molecule is in the $T G$ conformation in this case [14]. The $T T$ form is believed to exist in tho liquid state together with the other two forms.

A normal coordinate analysis of each isomer has been done on the assumption that the $\mathrm{CH}_{2}$ group is a point mass [14]. We have computed the normal vibrations for the three isomers, with inclusion of all hydrogen atoms and with the valence force field which was used for the other nitriles. The calculated frequencies are compared with the observed bands in Table 8. (We have observed the infrared spectrum of the liquid down to $200 \mathrm{~cm}^{-1}$, and find the three new low-frequency bands listed in Table 8.) It will be seen that the bands can be assigned quite well on the basis of the structural assignments to solid and liquid phases made by MATSUBARA [14]. The average deviations in frequencies of $1.13 \%, 1.01 \%$ and $1.21 \%$ for the $T T$, $T G$, and $G G$ isomers respectively are in the same range as those obtained for the other nitrile molecules, and suggest a satisfactory assignment.

Acknowledgment-This research was supported by a grant from the National Science Foundation. 